\title{
REPRISES: SEEING LIKE AN AUTHOR: EARLY BAKHTIN FOR ANTHROPOLOGISTS
}

$\mathrm{I}_{8}^{\mathrm{n}}$ $n$ the fall of 2019, I was part of a reading group at Indiana University devoted to reading Bakhtin's early works, Art and Answerability (1990) and Towards a Philosophy of the Act (1993). These texts were handwritten first drafts, never edited by Bakhtin himself for publication, published in Russian only after his death, and inaccessible to a broader readership until Vadim Liapunov translated these texts into English in the early 1990s. Sentence by sentence, the texts' unedited nature shows-so many sentences had vague referents that I constantly found myself retracing my steps to remember what relationship was being described in the passage as a whole, or which type of Being or Otherness Bakhtin was analyzing. It would take me an hour to read ten pages, a snail's pace in comparison to my usual gallop through pages.

Yet I kept devoting the time in the middle of a busy semester because I was captivated by 'what-if's'. At first the what-if was personal. Bakhtin's early work can be read as his answer to Kant and what was then recently circulated Husserl. I had spent my undergraduate years reading Continental philosophy, and only became an anthropologist because of similar disenchanted yet much less well-articulated critiques of the German philosophical tradition that Bakhtin so skillfully lays out in Towards a Philosophy of the Act. I began to wonder if I would have become a philosopher if Bakhtin's work had been more influential at the time of his writing in the 1920s. But when my reading group turned to reading 'Author and Hero in Aesthetic Activity' from Art and Answerability, my 'what if' question shifted to a disciplinary question-what if the authors of Writing Culture (1986) had wrestled with the concerns about reflexivity along the lines that Bakhtin raises? How would the anthropology of the 1990's have been different if anthropologists understood what it meant to be a writing subject describing Others the way that Bakhtin did? These questions are undercurrents in this essay, as I summarize what early Bakhtin has to offer contemporary anthropology so that you, gentle reader, might make a more informed decision about whether it is worth tackling this exhaustingly dense prose yourself, since these are manuscripts less concerned with specific novels or utterances than with the nature of Being and the underlying relationality of the self.

\section{REPRESENTATION AND THE EVERYDAY}

Bakhtin's overarching argument in both texts is one that his later work will reference occasionally: whatever analysis a person can make is crucially shaped by the fundamental relationship they have with the interactions they are contemplating. Analyzing the messy complexities of daily interaction entails a different set of possibilities and limitations compared to the analysis of an art form or philosophical text entails. Lived life, in short, is epistemologically different than represented life. If pushed, perhaps Bakhtin might suggest that lived life is richer and more unpredictable than a philosophized life examined through a bounded text, so Kant's philosophy may be more restricted than children playing. And certainly no one could compose 
a philosophized life without being enmeshed in lived life, although the reverse is not trueit is possible to live without philosophy. Yet when Bakhtin turns to comparing art and lived experience in 'Author and Hero', his preferences are no longer easily decipherable. Living life is different than writing, acting, or sculpting, but in the moment of living life, representing life is always just around the corner, so to speak, and both can mutually inform each other. The differences are worth unpacking, but to declare one better would be an error. A strong preference one way or another means not fully appreciating the multiple ways one can be in the world.

At any moment, as a reader struggling to parse these texts, one has to keep track of two possible ways of being in the world: the affordances of a lived life and the affordances of a represented life. In Towards a Philosophy of the Act, Bakhtin is principally concerned with the represented life that is at one and the same time the philosophized life. In 'Author and Hero in Aesthetic Activity', he no longer is concerned with how philosophers represent the world, but rather primarily with artists, and the distinction between aesthetic representation and lived experience. This representation can take place through the written word, through acting, through painting, through sculpting. The medium is much less relevant in 'Author and Hero' than the fact that this is a representation. Yet both theoretical and aesthetic forms of representation are relevant to anthropologists, since ethnography itself dwells uneasily between the dilemmas of aesthetically represented lives and philosophized or theorized lives.

For both texts, Bakhtin's fundamental distinction is between existing and representing existence. Thus from the outset, an irony haunts both author and reader-Bakhtin is describing (and occasionally privileging) lived life, the back-and-forth uncertainty of interacting with other unpredictable and equally mortal beings, through a philosophical text whose central conceit is the inadequacy of representation to fully capture lived experiences. Bakhtin's take on lived experience will seem familiar to readers more knowledgeable about his later work. Lived experience is always building on past experiences and calling forth new ones, but always uniquely and historically situated. Context, from this perspective, is an imperfectly bounded part of the continual flow of utterances or acts that emerge from what has taken place beforehand and at the same time anticipate future acts. Each of these interactions are distinct and neverrepeatable, they are deeply enmeshed in the moment in which they happen. One can never copy a lived moment, one can only repeat it with a difference, a difference generated by being situated in another moment of time than the author/artist/theorist was in the act of creation.

Here lies a fundamental difference between lived experience and represented experience: only representation travels, and every act of repeating a representation is in fact only ever partially a repetition. Every time someone encounters a representation, they live that representation anew and in that moment they put effort into actively bringing the representation into the lived world. Thus every experience of a representation is also always a new moment, a unique and historically situated experience of that representation.

And, to return to Bakhtin's paradoxical position when writing: only a philosophical representation can allow anyone to discuss what lived experience is like. Like anthropologists, Bakhtin struggles with the inadequacy of the reflexive relationship he must adopt to talk about the complex messiness of living moment by moment, a way of being that inevitably exceeds its representation. To write is to misrepresent, but only writing analytically can allow people to 
distinguish between existing and representing.

Thus Bakhtin's entire endeavor is built on presupposing its inadequacy, but it is a specific inadequacy-what one can know through representing is always inevitably different than what one can know through living. And only representing allows one to contemplate what one can know through living in a form that can traverse contexts. Analysis that can travel across contexts is analysis presented through representation, and thus for Bakhtin, this is analysis performed through a fundamentally different epistemological perspective than how one analyzes while experiencing life. What one knows about lived life in the moment of living is bound to that particular moment. Bakhtin believes that every lived moment is like no other, specific to its time and place. Thus while living life is not devoid of analysis, it is the case that the analysis one can perform in these moments is enmeshed entirely in that moment (that is, not represented and thus able to travel across contexts).

Lived analysis is not only bound to context, it is also part of a larger and continual stream of dialogue and interaction that is inherently incomplete because an act always anticipates an answering act. When one tosses a ball, someone else catches it and throws it back, or one has to search for the ball in the grass. When one gives a gift, someone else receives it, and responds. Even an absence of response is re-interpreted in daily life into a response-not acknowledging someone's gift prompts conversations about what that silence might mean. Every experience is always an answer or response to what has occurred beforehand and calling forth an answer or response.

For Bakhtin, when a tree falls in a forest, it makes a noise. But it is not a given that when someone paints a tree (dying at the last stroke, and so never seeing the painting in a moment separate from its creation) and no one else ever sees the painting, that the painting functions as a representation. The reflexive relationship one has when recording experience may be able to traverse context, but it is only when a representation enters lived experience that it can be answered. And when it enters into this lived moment, it is transformed, it is made into a unique act that is caught by that specific and never-repeatable set of interactions. Thus for Bakhtin, the moment that lived life and represented life come closest together is in the very act of creation or interpretation, when an author or sculptor is physically making the object or the beholder is engaged with the art form. Even then, understanding the representation being produced requires a different perspective with its own possibilities and limitations than what it means to be engaged in the physical act of creation. This is why I had to add a parenthesis at the beginning of this paragraph, positing that the painter dies just after making the last stroke, and thus never contemplating the painting as a beholder. ${ }^{1}$ In general, lived experience is profoundly historical and situated in time without any labor to make it so. By contrast, representation is always being actively introduced into a temporal moment by creators or interpreters, made distinctly relevant to that moment, and subsequently set aside as people stop paying attention to that representation, and then introduced anew at another moment. ${ }^{2}$

Bakhtin's overarching critique of philosophers in Towards a Philosophy of the Act is that too many conflate representation and lived life, or, worse, believe that their philosophical musings can adequately capture daily interactions. Representation in and of itself is not misleading, it is only when someone views represented analysis as one and the same as lived analysis that philosophical errors abound. 'Being that is detached from the unique emotional-volitional 
center of answerability ${ }^{3}$ is a rough draft, an unacknowledged possible variant of onceoccurrent Being; only through the answerable participation effected by a unique act or deed can one get out of the endless draft versions and rewrite one's life once and for all in the form of a fair copy.' (1993: 44) To believe that there is anything universal or capable of being analytically abstracted from the interplay of day-to-day singularities is to misunderstand representation's connection to lived experience. Philosophical representation cannot exist without abstracting from lived experience, but in the process of representing life in philosophical terms, the very qualities that make life distinctive is overlooked-the historicity of every action, the ways in which action is always a response that in turn calls forth an answer. In the case of those who overvalue philosophical representation, they are privileging the parasite instead of the host.

This critique may seem familiar to readers acquainted with the later Bakhtin Circle's criticism of Saussure, which also largely revolved around the argument that Saussure misunderstood the kind of reflexivity both a theorist of language and a speaker adopt in relationship to spoken words (Morris 1997). ${ }^{4}$ The Bakhtin Circle's primary objection to Saussure's model is that it compels the scholar to misrecognize how language functions, to disregard their own reflexive experiences of language. Part of the misrecognition lies in believing that a synchronic system, langue, can exist in the first place. Admittedly, Saussure himself did not claim that the synchronic system of language is in fact accessible to the speaker, only to the analyst. This however, was an error according to the Bakhtin Circle. Their first move is to ask: what must the analyst ignore or actively not know in an attempt to have a relationship to language that is by its very nature denied to the speaker of a language? Or, in other words, what must the analyst do to remove themself from the relationship between a speaker and a language or parole, and enter into a relation with langue? They first dismiss the idea that one uncovers langue simply by studying language from an omniscient perspective. To see language with a truly omniscient gaze would be to see constant transformation, to see constant overturnings of the underlying norms that langue is supposed to offer. There is no moment in which language appears to stand still long enough for one to discern the rules underlying its usage. Thus, this synchronic perspective is a fiction inaccessible to someone who is viewing language from, as the Bahktin Circle puts it, a 'truly objective viewpoint.' (Morris 1997: 32)

The authors then ask if perhaps langue might exist for the subjective speaker of a language? If omniscience undercuts an experience of language as langue, perhaps, despite Saussure's claims to the contrary, a subjective speaker might have access to langue. The Circle rejects this notion since the speaker of a language does not see the language as a system of normatively identical forms. What matters most for the speaker is not the ways in which the norms in a language exist, but how to connect linguistic resources to a new context to be able to communicate in the moment. The reflexive stance a speaker has to language is to see language as perpetually adaptable, as a tool for connecting to new contexts and for constituting and reconstituting social relations. The speaker is interested in signs not because they are stable and self-equivalent, but precisely because they are mutable and constantly adaptable to contexts.

Thus the Bakhtin Circle argues that the synchronic perspective on language is one that can only occur from a very particular reflective stance-a metalinguistic stance which is 
committed a priori to uncovering a specific type of homogeneity, to uncovering similarities in speech acts that can be generalized. This metalinguistic stance is a central way in which reflexivity can lead to misrecognition by overlooking the complex and multiple ways in which speech and context are intertwined.

In addition, this focus on the principles of homogeneity underpinning language misrecognizes how meaning is produced-the ways in which the verbal consciousness of the speaker processes speech acts. Speakers do not understand speech acts in terms of how they are connected to a synchronic linguistic schema, and thus in terms of correctness and incorrectness. Instead, when one understands a statement, one is evaluating in terms of a wide range of criteria: whether there is enough truth in the statement, whether it is compelling or convincing, whether the statement resonates with one's own emotions, whether the statement offers insight, and so on.

The Bakhtin Circle does not view academic reflexivity as the sole source of misrecognition. They also suggest that speakers misrecognize their own linguistic agency when they speak, that the reflexive stance of the speaker is to see the words they utter as their own, that whatever they utter, they will tend to view as their own formulations. This, of course, is a misrecognition. The words we speak are also always other people's words. The language we utilize is not devoid of intentions, only waiting for us to animate words. Instead, as Bakhtin puts it, language 'is populated-overpopulated-with the intentions of others.' (Bakhtin 1981: 294) That is, speakers tend to reflexively engage with their own language as monological, although this is a misrecognition of a speaker's own heteroglossia. Throughout this discussion of Saussure, the Bakhtin Circle's take on reflexivity strongly resembles Bakhtin's early discussion of the contrast between a philosopher's take on Being and what lived experience truly consists of. While in Towards a Philosophy of the Act, there is no parallel to an account of the speaker's monological misrecognition, in his subsequent work, 'Author and Hero in Aesthetic Activity', Bakhtin describes the self's perspective on social interaction as leading to a form of misrecognition in an equivalent manner.

\section{AUTHOR AND HERO}

If in Towards a Philosophy of the Act, Bakhtin asks what it means to be a theorist of lived experience, in Author and Hero he asks what it means to be a writer of lived experience. While he shifts to questions of creation in acts of representation, he still insists that point of view is foundational-that one cannot understand what is involved in representing how another lives without understanding the potential and limits of one's vantage point. In exploring the situatedness of a perspective in his early texts, he is not overtly insistent on the categories that contemporary anthropologists use to clarify the distorting lens of a subject position-not so surprisingly given his own historical period, he offers no discussion of how gender, ethnicity, class, or sexuality shape interpretation. His focus is on how one's perspectival origin point shapes what it means to be a self interacting with or writing about an other who also experiences the world as a self. Throughout this work, a reader has to track if Bakhtin is describing the self who is a person in the world, or the self of an author, or the self of a hero/character.

In analyzing the viewpoint of a hero, Bakhtin is not only focused on a protagonistthe 'hero' in his framework is anything constructed by a creator as having a perspective. The hero does not even have to be actively created by the author to be seen as having their 
own perspective-Bakhtin writes that as people prepare to see objects aesthetically, they turn the objects into heroes.

When I am in the presence of a simple figure, color, or combination of two colors-in the presence of this actual cliff or this surf on this particular seashoreand I attempt to find an aesthetic approach to them, the first thing I must do is vivify them, make them into potential heroesthe bearers of a destiny... I may be frightened by the menacing aspect of the animated sea, I may come to feel pity for the constrained cliff (1990: 66)

While anything in the world can be turned into a character or hero, in order to be a character, one must have an author. The burden of the character is to always be the object of someone else's perspective, and yet with a perspective of their own.

If one was to think of the hero as one's informant being described in an ethnography, then this is truly an ethical dilemma for the ethnographer. The very act of writing about someone distorts the ways in which they exist in the world. One's description inevitably renders one's informant as a totalized character with a perspective, yet an ethnographer wants to do justice to their interlocutors' lived complexity, excess, and incompleteness.

In 'Author and Hero', there is a passage in which, as an anthropologist, I heard eerie resonances with fieldwork as Bakhtin addresses the difference between playing and a theatrical performance, between being immersed in the dialogic flow of life and addressing an audience. He explains that the 'as-if' of play is not enough to move the participants into a representational relationship with the world.
He describes in evocative detail how when boys play at being robbers, travelers, and policeman, they are wholly committed to their roles. They are not producing art, they are not engaged in representing the world, they are simply being a different role than they usually inhabit in that moment.

The boy who plays a robber chieftain experiences his own life (the life of a robber chieftain) from within himself: he looks through the eyes of a robber chieftain at another boy who is playing a passing traveler, his horizon is that of the robber chieftain he is playing. And the same is true of his fellow players. The relationships of each of the players to the event of life they have decided to enact (the attack of robbers on a group of travelers) is no more than the desire to take part in that event, to experience that life as one of its participants: one boy wants to be a robber, another-a traveler, a third-a policeman, and so forth. But his relationship to life as a desire to experience it himself is not an aesthetic relationship to life. (1990: 74)

For those who are playing, this is an opportunity to act as-if one could be in a different starting point into the river of life, but still very much part of the lived experience. A few pages later, Bakhtin describes how actors are always moving rapidly between playing and being an artist. When an actor plays, they have the same relationship to their character that the boy playing robber chieftain has. When the actor starts contemplating the play as a whole, and how the character they inhabit contributes to the structure of the narrative, then they are acting as a creator/interpreter. Actors, like ethnographers, can shift rapidly between these 
two distinct relationships to being in the world (1990: 76-79).

To return to the boys' play, this interaction only becomes a represented or aesthetic experience when a spectator enters, someone who observes but does not participate. In Bakhtin's description of the spectator, there are echoes of the ethnographer, who 'begins to admire the children's playing from the standpoint of the whole event of a life represented by their playing.' (1990: 75) The spectator engages with this moment of play as an encapsulation of larger patterns, or other moments. They begin to see the event as repetition and reflection, and in terms that remove the interactions from the immediacy of that moment. 'It should be evident, however, that, in doing so, he alters the event as it is initially given: the event becomes enriched with a new moment, new in principle - an author/beholder, and, as a result, all other moments of the event are transformed as well, inasmuch as they become part of a new whole' (ibid.) The spectator, through their contemplation, transforms play into the seeds of a theatrical performance, but it could just as easily be a scene in a novel, or in an ethnography. Theater play, novel, ethnography - all three create (for those portrayed) a bounded totality, a completeness, that the boys actually playing do not experience. Just like Bakhtin's spectator, the ethnographer is always only partially in the moment of lived experience, and also regularly anticipating writing, planning the field notes they are about to scribble, wondering about the chapters or articles that might be sparked by what they have just witnessed. ${ }^{5}$

It is not only being a spectator or an ethnographer that removes one from lived experience. Indeed, analyzing as a self, for Bakhtin, also creates a relationship that leaves one alongside but not fully immersed in the realm of lived experience. Lived experiences are not interactions of selves, they are interactions of others. Whenever someone interacts with you, that person views you as an other, and that person is an other for you. This person is incomplete to you, you cannot know all there is to know about them-unlike an author, who can in fact know all that there is to know about a character that they are creating. When you perceive the interaction from your own vantage point, that is as a self, simply interpreting lived experience as a self distorts it. 'And the other person's $I$ is also experienced by me in a manner which is completely different from the manner in which I experience my own $I$ : the other person's $I$ is also subsumed under the category of the other as a constituent feature of him.' (1990: 38) Here Bakhtin lays out the misrecognition that every self brings to interpreting living side by side with others. What we know of others is fundamentally different than how we know ourselves. While in this passage, Bakhtin emphasizes that how we know ourselves is distinct from how we know every other being in the world, he moves on to point out that others can never know us as we know ourselves. Thus lived experiences is an ever-expanding compilation of people who can never fully know who or how they are for others. Yet what can be known is that from another's perspective, you are not a self, you are an other. In terms of lived experiences, the opposite of the other is not a self, the opposite of the other is another other. We all live in this space of only others, and yet have only an abstract form of contemplation as a way to access it that is epistemologically removed from lived life. It is the limitation of representation that this realm of otherness can never be depicted-representation by its very nature entails a self imagining how others are in the world. A world only of others, after all, 
is a world without a view point that can be articulated.

Bakhtin does suggest that even when one thinks as a self, it is not selves all the way down. He discusses how the self has roots in always already being an other in an evocative passage about how a child learns language.

The child begins to see himself for the first time as if through his mother's eyes, and begins to speak about himself in his mother's emotional-volitional toneshe caresses himself, as it were, with his first uttered self-expression. Thus, he uses affectionate-diminutive terms in the appropriate tone of voice in referring to himself and the limbs of his own body'my footsies,' 'my tootsies.' 'my little head,' 'go night-night,' 'nightie-night.' (1990: 50)

The very words that a child uses to express themselves are already another person's words. Bakhtin was writing at a time that many other social theorists turned to the mother-child relationship as the source of an ideal origin myth for the construction of a self. It is telling that for Bakhtin, this originary relationship is the anti-thesis of an origin-the child uses words to start framing a self that the mother provides, but these are words that the mother's mother also used. The child becomes a social self through a world of others' words.

There are other passages in which Bakhtin unsettles the completeness of the self that interacts with the world. Both in this text and in Philosophy of the Act, Bakhtin describes how the self's attempts to know an other are always incomplete, and also enriching. Empathy according to Bakhtin is a moment in which one experiences the limitations of one's perspective. He views empathy as an act of projectionone imagines oneself into another person's historically specific subject position. Yet doing this fully is impossible. A complete immersion into another's perspective would be to deny one's own situated location in the world. In 'Author and Hero' he writes:

Strictly speaking, a pure projection of myself into the other, a move involving the loss of my unique place outside the other, is, on the whole, hardly possible ... Referring what I myself have experienced to the other is an obligatory condition for a productive projection into the other and cognition of the other, both ethically and aesthetically. Aesthetic activity proper actually begins at the point when we return into ourselves (1990: 26)

Thus to understand another's point of view, at best one can project oneself as best one can into their perspective, and then return back to one's own vantage point, illuminated by how much a shift in perspective expanded what one can know. Empathy done well is never a complete immersion, it is always an exercise in learning the limitations of being a situated being.

Authors, however, experience different limitations when they are imagining the lives of their characters. While others who encounter each other in the realm of lived experiences are equally incomplete to each other, this is not the case for the author-character relationship. The author is always incomplete, a living being who is immersed in the "uninterrupted flow of deed-performance.' (Liapunov in Bakhtin 1993: xix). Indeed, in the triad of authorcharacter-reader, for Bakhtin, only characters are complete. Everything that can be known about them is already in the text-they are a complete totality in a way that living people can never be (for an alternative anthropological take on the distinction between author and 
hero, see Yurchak 2006: 134). Thus readers too are incomplete, because they-like authors and unlike characters - are engaged in the daily flow of life. Bakhtin makes a point throughout the text of equating the author with the beholder or reader. From Bakhtin's perspective, they are both deeply immersed in lived experience and turning in the moment of creating or beholding towards a relationship of representation. As a result, authors and readers experience the otherness of a hero as fundamentally different than the way authors/readers experience others in their daily lives.

Taking the differences between author/ reader and character seriously would alter the ways in which ethnographers thought about the challenges of writing about others' lives. Reading Bakhtin as he articulated this distinction reminded me of an article I published in 2009, 'Living Theory', in which I distinguished between British structural functional analysis as it is written and British structural functional analysis as it is lived, since my Samoan interlocutors tended to analyze the world in ways fairly resonant with structural functionalist thought. ${ }^{7}$ For example, both structural functionalists and Samoans sorted the people they interacted with through social roles-interacting with one's second cousin was different than interacting with one's minister, although one person might be in both roles. In monographs, structural functionalists could describe the obligations of each role, without wondering how they might conflict in practice. Yet my Samoan interlocutors faced the dilemma of multiple roles on a daily basis, always watching for how the context shaped which role would dominate for that stretch of interaction. For ethnographers, multiple social roles generated the task of mapping, while for social actors, multiple social roles generated specific social strategies and uncertainties
(Gershon 2009: 403-404). Ethnographers, in short, are shifting potential ways of knowing and accounting for other people's practices through the very act of writing about them, transforming their informants from complicated and incomplete beings into knowable characters on the page.

This distinction between author and text, and author and character, re-appears in Bakhtin's later writings, including in the conclusion to 'Forms of Time and of the Chronotope in the Novel.' He insists in these paragraphs that the lived world and the represented world are fused, but forever distinct. The author voiced by the text is always a different being than the biographical author who puts pen to paper, or fingers to a keyboard, yet these distinct forms of authors are interconnected.

However forcefully the real and the represented world resist fusion, however immutable the presence of that categorical boundary line between them, they are nevertheless indissolubly tied up with each other and find themselves in continual mutual interaction; uninterrupted exchange goes on between them, similar to the uninterrupted exchange of matter between living organisms and the environment that surrounds them. (...) The work and the world represented in it enter the real world and enrich it, and the real world enters the work and its world as part of the process of its creation, as well as part of its subsequent life, in a continual renewing of the work through the creative perception of listeners and readers. (1990: 254)

What is the reason that the lived world and the represented world have this peculiar relationship with one another? It is only after reading early Bakhtin that $I$ know he is a bit too 
speedily gesturing to a larger argument he has made in his 20s that the reflexive relationship one has with the real world, in which one is always engaged in incomplete acts that answer previous performances and call forth new ones, is in contrast to the represented world in which time is bounded and characters' total being can be encapsulated. Author and listener/ reader are one in this passage too, for both author and beholder are faced with the task of experiencing the aesthetic object in lived time. They are always fusing the lived world with the represented world by interpreting the text through their own unique embodied historically specific experiences. This is why Bakhtin concludes by describing the author as both outside of the text and creating the text-it is this double-voicing in which two ways of being in the world, representing it and living it, exist in the same moment. This moment becomes a 'special creative chronotope' (1981: 254), a fusion that occurs whenever someone encounters the aesthetic object in lived time again (1981: 257).

\section{CONCLUSION}

Let me return now to my 'what if' questionhow would anthropology be different if anthropological concerns with reflexivity and representation in the 1990s had started with the conundrums raised by Bakhtin's early framework? Recall that Writing Culture (1986) requested that anthropologists think of ethnographies as literary productions, deeply enmeshed in the politics of their historical moment. Those authors suggested that ethnographers should take into account how representing their fieldsite was part and parcel of larger historical patterns of unequal distributions of access and control. Bakhtin might not have disagreed - all texts for him were literary creations emerging from their historical moment, but his emphasis on the trouble with ethnography would be firmly located in the epistemological divide between representing experience and living it. Early Bakhtin offers a different set of questions around reflexivity to supplement the questions anthropologists are currently more familiar with.

I have been suggesting throughout this essay that representing people's lives would inevitably be seen as a necessary but flawed act if one begins with early Bakhtin. Ethnographers write about people who are living incomplete lives, whose acts in the world still call forth answers, and turn them into a text in which the act of being represented presumes a totality (because all representation presumes a totality according to Bakhtin). Meanwhile all involvedauthor, reader, person being represented-know this totality is not in fact the case. Indeed, Bakhtin (1990: 163-166) describes a parallel conundrum in his discussion of biography. Thus ethnographers could become more conscious that the kinds of social analysis they perform will be different from the kinds of social analysis their interlocutors produce as their interlocutors interact strategically, engaging with the social problems that their way of life regularly and reliably provides. Writing about how others' lives would always be seen as producing a totality that erroneously portrays what people's lived experiences are like, simply because analysis produced through representing and analysis produced through living provide such different takes on being in the world. Ethnographers thus often feel vexed, they are taking a snapshot of a moving dialogue that structurally incorporates a power relationship that most ethnographers would like to disavow-after all, ethnographers also live in the messy flow of answerability and our fieldwork interlocutors are often authors in a Bakhtinean sense in their own lives too. Yet when an ethnographer writes, they are living the 
incomplete life of authorship and turning their fieldwork interlocutors into complete beings in their texts.

At the same time, engaging with other people's representations would not be engaging with this foundational rift between living life and representing it. Analyzing a play rehearsal is different than analyzing how people shop for food in culturally specific ways. In this 'what if' world, ethnographers would widely acknowledge that analyzing representations-myths, theatrical performances, dance, storytelling, and so on-are moments in which the ethnographer and their fieldwork interlocutors are on the same existential wavelength, so to speak, and wrestling with similar conceptual dilemmas. Both are engaging with characters that are as complete as they ever will be in the representation-after all, every representation enables a totality and completeness to a life that can never be realized in lived experiences. In addition, representations produced by both the ethnographer and the ethnographic informant are both able to travel across contexts (albeit through different circuits of circulation), and in doing so, allow multiple people to engage with representations in a wide range of situations. In the process of engaging with these representations, everyone then labors to connect these representations to new historical moments through interpreting, regardless of the origin of these representations. In short, beginning with Bakhtin would change the way ethnographers currently think about their alignments and misalignments with their fieldwork interlocutors. After all, for Bakhtin, the difference between an Irish-American debt-ridden ethnographer in their 20s and a Kayapo middle-aged storyteller is not so great in the moment of narrating as the gap between the same ethnographer writing fieldnotes and a Kayapo hunter searching for prey.
Finally, if anthropologists began with Bakhtin, then we would ask another set of questions alongside the questions that Writing Culture inspired many ethnographers to ask about how a situated self interprets their ethnographic encounters. Anthropologists would also be concerned with how their fieldwork interlocutors understand them as others toopaying careful attention to the other others in that context to whom the ethnographer might be compared. Some ethnographers have already argued for this type of analysis (see, among others, Behar and Gordon, eds. 1995). Phil Parnell (1992) could only understand how activists in a Manila squatter movement treated him (occasionally) by seeing when and how they viewed him as comparable to government officials they also had to manage. Ira Bashkow (2006) proposes that simply asserting that he was a white man doing fieldwork is not an illuminating enough claim to explain his subject position; he has to understand how Orokaiva people think about whiteness and the other white people they have previously encounters, and who Orokaiva are likely to compare him to. In short, to begin one's ethnography with early Bakhtin's insight might not, as many ethnographies currently do, involve describing what one's subject position is in the terms that U.S. anthropologists use as a quick and slightly too abbreviated a shorthand for complex historical trajectories-gender, ethnicity, sexuality, age, and class. Rather, one might align with Bashkow, Parnell, among others, and explain what kind of other the anthropologist was in their fieldwork site, exploring the variety of others to and from whom they could be compared and distinguished. 


\section{NOTES}

1 This distinction is vividly apparent in his description of the actor-who, in his account, moves rapidly between fully inhabiting the perspective of their character and understanding their character's relationship to the play as a whole (1990: 76-78). 'For, just as much as the author and the director, the actor creates a particular hero in association with the artistic whole of a play, as a constituent in that whole.' (1990:77) While the actor is occasionally an artist-like the author or director, Bakhtin also argues that the artist sometimes also operates not as a creator but as if from a different lived position, like a boy pretending to be a brigand, as I discuss later. 'When, on the other hand, the actor, in playing his role, 'reincarnates' bimself in the hero, then all these constituents of forming the hero from outside become transgredient to the actor's consciousness and experiencing as the hero.' (1990: 78)

2 Every discussion I can find of this point is longwinded and requires considerable explanation of the textual references that were laid out in the previous pages. For example, 'From the very outset, sympathetic co-experiencing introduces values into the co-experienced life that are transgredient to this life; it transposes this life from the very outset into a new value-andmeaning context and can from the very outset rhythmicize this life temporally and give it form spatially' (1990: 83).

3 Answerability here is what I have been calling lived experience, or the events that are being lived and not represented.

4 Contemporary linguistic anthropologists have taken this critique of Saussure onboard, my focus here however is on internal consistencies in Bakhtin's work, not tracing his influences in contemporary research.

5 In my own intertextual repertoire, this resonates with how Marilyn Strathern opens her book, Property, Substance and Effect (1999).

6 Please do not take the charm of these quotes as a sign that the rest of these texts are as playful or accessible. Even Michael Holquist writes in his introduction to Art and Answerability: 'One reason why Bakhtin has so quickly become popular with so many [and varied] readers is that they have found him easy to read, at least by comparison with other theorists now competing for attention. These texts, by contrast, are extremely difficult, and make demands on the reader's erudition, power of synthesis, and sheer patience not encountered in the books that have defined Bakhtin's achievement in the recent past.' (1990: ix) Please do not be misled, I happen to be fairly good at choosing quotes.

7 While some anthropologists have been fortunate enough to discover Agamben or Heidegger in the wild, so to speak, not all anthropologists are lucky enough to find their fieldwork interlocutors resembling trendy or evergreen philosophers.

i Acknowledgements

I might never have read these texts if Patrick Michelson had not organized this reading group for the Center for the Theoretical Inquiry in the Humanities. I am also grateful to Vadim Liapunov for coming to the reading group with such regularity, and providing his insights as the translator. Melissa Demian offered encouragement via Facebook Messenger. Meghanne Barker, Summerson Carr, Andy Graan, Ilya Kliger, and Susan Lepselter were especially kind in helping me try to anticipate and even perhaps avoid some unfortunate interpretations of my sentences.

\section{REFERENCES}

Bakhtin, Mikhail 1981. The Dialogical Imagination: Four Essays. Translated by Caryl Emerson and Michael Holquist. Austin: University of Texas Press.

Bakhtin, Mikhail 1990. Art and Answerability: Early Philosophical Essays by M. M. Bakbtin. Translated by Vadim Liapunov. Austin: University of Texas Press.

Bakhtin, Mikhail 1993. Toward a Philosophy of the Act. Translated by Vadim Liapunov. Austin: University of Texas Press.

Bashkow, Ira 2006. The Meaning of Whitemen: Race and Modernity in the Orokaiva Cultural World. Chicago: University of Chicago Press. https://doi. org/10.7208/chicago/9780226530062.001.0001.

Behar, Ruth and Deborah Gordon (eds) 1995. Women Writing Culture. Berkeley: University of California Press. 
Clifford, James and George Marcus (eds) 1986. Writing Culture: The Poetics and Politics of Ethnography. Berkeley: University of California Press.

Gershon, Ilana 2009. Living Theory. Critique of Antbropology 29 (4): 397-422. https://doi.org/10.1177/0308275X09345416.

Morris, Pam (ed.) 1997. The Bakbtin Reader: Selected Writings of Bakhtin, Medvedev, Voloshinov. London: Bloomsbury.

Parnell, Philip C. 1992 Time and Irony in Manila Squatter Settlements. In Carolyn Nordstrom and JoAnn Martin (ed.) The Paths to Domination, Resistance, and Terror. Berkeley: University of California Press.
Strathern, Marilyn 1999. Property, Substance, and Effect: Anthropological Essays on Persons and Things. New York: The Athlone Press.

Yurchak, Alexei 2006. Everything was Forever, Until It was No More: The Last Soviet Generation. Princeton: Princeton University Press.

\section{ILANA GERSHON}

PROFESSOR

DEPARTMENT OF ANTHROPOLOGY

UNIVERSITY OF INDIANA

BLOOMINGTON

igershon@indiana.edu 